\title{
Total Respiratory Inertance and Its Gas and Tissue Com- ponents in Normal and Obese Men *
}

\author{
J. T. Sharp, J. P. Henry, S. K. Sweany, W. R. Meadows, and \\ R. J. Pietras \\ (From the Cardiopulmonary Laboratory of the Veterans Administration Hospital, Hines, Ill., \\ and the Departments of Medicine of the University of Illinois College of \\ Medicine and the Stritch School of Medicine of Loyola University, \\ Chicago, Ill.)
}

Total respiratory inertance may be defined as that component of the total impedance to breathing that relates to acceleration of respiratory gas and of all tissue elements (lungs, rib cage, diaphragm, and abdominal contents) that move during respiration. It is expressed in units of pressure required to overcome this inertial component of the total impedance and produce air flow acceleration of $1 \mathrm{~L}$ per second per second. Thus its units are centimeters $\mathrm{H}_{2} \mathrm{O}$ per liter per second ${ }^{2}$. Intuitively, one would suspect that the inertance of the chest and the abdomen should be increased in severely obese subjects. In investigations of total respiratory mechanics in excessively obese persons, we made measurements of total respiratory inertance. In addition, we attempted to separate the total respiratory inertance into its gas and tissue (including lung tissue, chest wall, and abdominal) components in three normal and three excessively obese subjects. These data form the substance of this report.

Inertance data on the normal human respiratory system were first published by DuBois, Brody, Lewis, and Burgess (1) in 1956. These authors, assuming that the respiratory system behaves mechanically as a simple or "lumped" physical system, determined the total compliance and the natural frequency of the respiratory system. They then calculated the total inertance of the respiratory system by using the simple physical relationship by which the natural frequency of a system may be predicted if its elastic and inertial characteristics are known: $f_{n}=1 / 2 \pi \sqrt{1 / I \cdot C}$, where $f_{n}$ is the natural frequency, $I$ is the total inertance,

\footnotetext{
* Submitted for publication July 5, 1962 ; accepted November 21, 1963.

Supported in part by National Institutes of Health grant H5124.
}

and $C$ is the total compliance. Their estimated value for total respiratory inertance was 0.0058 $\mathrm{cm}_{2} \mathrm{O}$ per $\mathrm{L}$ per second ${ }^{2}$, a value which, though measurable, is small enough to be neglected in normal subjects at ambient pressures and at the air flows and accelerations usually encountered. These authors pointed out that the respiratory system is more than critically damped, necessitating that the natural frequency be determined by examining the phase relationship between sinusoidal waves of driving pressure and the resulting oscillations of air flow. Estimates of natural frequency made in this way, together with measurements of the total respiratory compliance, constitute the data from which inertances were calculated in the present study.

\section{Methods}

Of the 22 subjects studied, 8 were normal laboratory personnel of normal weight, and 14 were excessively obese persons varying in weight from 250 to 407 pounds. Of the obese subjects, 9 were otherwise normal except for slight arterial hypoxemia in 2 ; their $\mathrm{PCO}_{2}$ 's were normal. The remaining 5 subjects had the obesity-hypoventilation syndrome, although $\mathrm{PCO}_{2}$ values were normal in 3 at the time these studies were performed.

The total respiratory compliance was measured by a modification of the method of Heaf and Prime (2), in which steady negative pressures are applied to the surface of the subject's thorax, which is enclosed in a plethysmograph. Volume changes in mid position are plotted against changes in applied pressure, and the total respiratory compliance is computed from the resulting static volume-pressure curve based upon 8 to 25 volumepressure points. These measurements were made with subjects in a supine position. The natural frequency of the respiratory system was determined by Mead's modification of the oscillatory method of DuBois and associates $(1,3)$ (Figure 1 ). Sine waves of pressure were applied to the surface of the body using an electronic sine wave generator, power amplifier, and high volume displacement high fidelity speaker as a variable frequency 


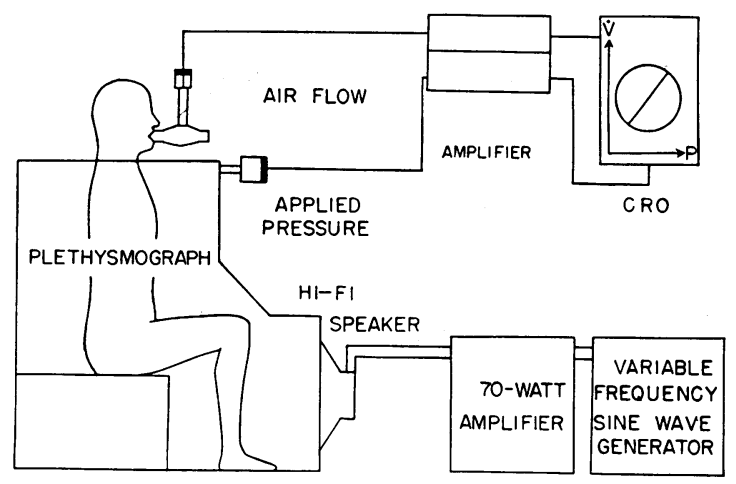

Fig. 1. The oscillatory Method USED to Determine THE NATURAL FREQUENCY OF THE RESPIRATORY SYSTEM. $\mathrm{P}=$ applied pressure $; \mathrm{V}=$ air flow $; \mathrm{CRO}=$ cathode ray oscilloscope. See text for discussion.

pump. Pressure waves of 2 to $3 \mathrm{~cm}$ water amplitude were produced, which were sensed by a Statham P23d transducer and applied to the horizontal axis of an oscilloscope. Air flow recorded at the mouth by a screen flow meter and a Sanborn gas differential pressure transducer was applied to the vertical axis of the oscilloscope (Figures 1 and 2). As shown in Figure 2, when air flow and applied pressure are plotted one against the other in this fashion, loops are formed at frequencies above and below the natural frequency. The loop closes and assumes the form of a diagonal line at the natural frequency of the respiratory system when driving pressure and resultant air flow are exactly in phase. In actual use, the frequency of oscillation was gradually altered while the oscilloscope was observed. During preliminary observations the vertical and horizontal gains were adjusted to give a large loop with an axis as close as possible to $45^{\circ}$ from horizontal. The determination was done with the subject relaxed with an open glottis at his mid position and moving no air on his own. These procedures were adopted because they allowed optimal discrimination between closed and minimally opened loops and increased the precision of natural frequency measurements. The frequency at which the loop closed was repeatedly determined while slowly decreasing the frequency from an initial value of 8 to 10 cps down to the range of the expected natural frequency ( 3 to $7 \mathrm{cps}$ ). The natural frequency then was approached repeatedly from lower frequencies, slowly increasing frequencies from 2 to 3 cycles, and the frequency at which the loop disappeared was again recorded for several such determinations. Approaching from high frequencies and from low frequencies, there was a gap of from 0.7 to $1.8 \mathrm{cps}$ between the frequencies at which the loop disappeared. The natural frequency was assumed to lie midway between the upper and lower limiting frequencies. This method of determining the natural frequency was found to be necessary because of the respiratory system's highly damped mechanical characteristics, which exclude sharp resonance. Once the natural frequency and the total respiratory compliance were known, the total respiratory inertance was calculated using the simple physical relationship previously cited, solved for the total respiratory inertance:

$$
I=\frac{0.0253}{\left(f_{n}\right)^{2} \cdot C}
$$

In three normal subjects and three excessively obese subjects, an attempt was made to measure separately the gas and the tissue components of total respiratory inertance. The subjects breathed gas mixtures of widely differing densities, which altered the gas inertance in direct proportion to the change in gas density but left tissue inertance unchanged. When two gas mixtures of differing but known density are breathed and the natural frequency determined during the breathing of each, both gas and tissue components of total inertance can be computed. The principle of this experiment and the calculation is shown in the two equations below. Breathing gas mixture 1 ,

$$
I_{\mathrm{tiss}}+D_{g 1} \cdot I_{o}=\frac{0.0253}{\left(f_{n 1}\right)^{2} \cdot C} .
$$

Breathing gas mixture 2,

$$
I_{\mathrm{tiss}}+D_{g 2} \cdot I_{g}=\frac{0.0253}{\left(f_{n 2}\right)^{2} \cdot C}
$$

$I_{\mathrm{t} \text { iss }}=$ inertance of all tissue elements in the lung, thorax, and abdomen moved during respiration; $I_{g}=$ inertance of gas in the respiratory system referred to the density of air; $D_{g 1}$ and $D_{g 2}=$ densities of the two gas mixtures breathed relative to that of air; $f_{n 1}$ and $f_{n 2}=$ natural frequencies determined during breathing of gas mixtures 1 and 2 ; and $C=$ total respiratory compliance.

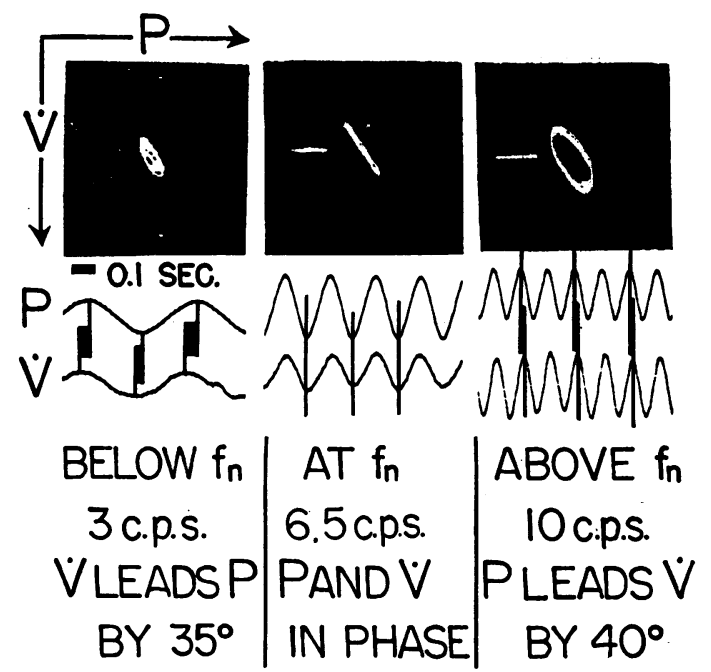

Fig. 2. Tracings and oscilloscopic plots of $P$ and $V$. The left panel shows the situation below the natural frequency $\left(f_{n}\right)$ where flow leads pressure, and the right panel shows the situation above the natural frequency where pressure leads flow. At the natural frequency, shown in the center panel, flow and pressure are exactly in phase. 
The gas densities, the natural frequency during the breathing of each gas mixture, and the total compliance may be directly measured. Simultaneous linear algebraic equations result, each describing conditions during the breathing of one of the gas mixtures. There are two unknowns, the gas inertance $\left(I_{\sigma}\right)$ and the tissue inertance $\left(I_{\mathrm{t} 1 \mathrm{ss}}\right)$, and the equations may be simply solved.

Three gas mixtures were used for these experiments, air, an $80 \%$ helium- $20 \%$ oxygen mixture, and an $80 \%$ sulphur hexafluoride-20\% oxygen mixture. With these mixtures, the data for the construction of three sets of simultaneous equations could be obtained, each set of which would yield a value for tissue and gas components of total respiratory inertance. Each gas mixture was breathed deeply and rapidly in an open circuit for approximately 2 minutes by the subject who was seated in the plethysmograph so that the measurement could be made immediately. A thin, supported 10-L neoprene bag was attached to the distal end of the screen flow meter to contain the gas mixture and prevent its loss from the system. The natural frequency with each gas was determined between four and six times and the values averaged. After each natural frequency determination, the subject expired maximally into an anesthesia bag, the contents of which were analyzed for nitrogen, oxygen, and carbon dioxide. The remaining gas was assumed to be the foreign gas, either helium or sulphur hexafluoride, and from the analyses, gas densities were calculated assuming full saturation with water vapor at $37^{\circ} \mathrm{C}$. Analyses following repeated natural frequency determinations were generally similar during the breathing of a single mixture inasmuch as the prebreathing of the mixture was repeated in the same manner. Hence the several gas analyses were averaged, and from this average a single gas density value was calculated. Gas densities were expressed relative to air, averaging 0.6 during helium breathing experiments and 3.5 during sulphur hexafluoride breathing experiments.

In addition, the lung inertance (inertance of lung tissue plus contained gas), breathing air, was determined in the three normal and the three excessively obese subjects in whom the differential gas density studies were done. Lung inertance was measured by the technique described by Mead (4) using an esophageal balloon catheter placed with its tip $40 \mathrm{~cm}$ from the nares. The balloon was $10 \mathrm{~cm}$ in length, $1.5 \mathrm{~cm}$ in diameter, and was used with an air volume of $0.4 \mathrm{ml}$. Movements of the head and neck failed to produce significant alterations in esophageal pressure. A low resistance Krogh spirometer, a screen flow meter, and Sanborn differential transducers were used, and measurements were made with the seated subject panting. Tracings of transpulmonary pressure, air flow, and tidal volume were made at paper speeds of $200 \mathrm{~mm}$ per second and accelerations determined by drawing tangents to the air flow curve at two points of zero flow at the ends of inspiration and expiration. The inertance pressures at these points were determined by subtracting the calculated elastic change in transpulmonary pressure between end-inspiration and endexpiration from the observed differences in the esopha- geal pressure tracings. The elastic pressure difference was calculated by dividing the tidal volume by the lung compliance previously determined during slow breathing. The resulting inertance pressure representing the sum of end-inspiratory and end-expiratory inertance pressures was divided by the sum of end-inspiratory plus end-expiratory accelerations to yield lung inertance.

\section{Results}

Total inertance. Table I gives data on total compliance, natural frequency, total respiratory inertance, and body weight in the 22 subjects. The mean inertance in the normal subjects was $0.0098 \pm 0.0005(\mathrm{SE})$ and in the obese subjects was $0.0253 \pm 0.0022$ ( $\mathrm{SE}$ ) $\mathrm{cm} \mathrm{H}_{2} \mathrm{O}$ per $\mathrm{L}$ per second $^{2}$. There were significant differences in total respiratory compliance $(p<0.01)$, natural frequency $(\mathrm{p}<0.001)$, and total respiratory inertance $(p<0.001)$ between the normal and obese groups. Total inertance was significantly correlated $(\mathrm{r}=+0.86, \mathrm{p}<0.001)$ with body weight as shown in Figure 3 . Total respiratory compliance also correlated significantly with body weight $(r=-0.74, p<0.001)$, as did natural frequency $(r=-0.64, \mathrm{p}<0.01)$.

Separation of gas and tissue components of total respiratory inertance. Table II gives the data

TABLE I

Inertance data in normal and obese subjects

\begin{tabular}{|c|c|c|c|c|}
\hline Subject & Weight & $\begin{array}{c}\text { Total } \\
\text { compliance }\end{array}$ & $\begin{array}{c}\text { Natural } \\
\text { frequency }\end{array}$ & $\begin{array}{c}\text { Total } \\
\text { respiratory } \\
\text { inertance }\end{array}$ \\
\hline & $k g$ & & $c p s$ & $\underset{\mathrm{L} / \mathrm{sec}^{2}}{\mathrm{H}_{2} \mathrm{O} /}$ \\
\hline \multicolumn{5}{|c|}{ Normal subjects } \\
\hline $\begin{array}{l}1 \\
2 \\
3 \\
4 \\
5 \\
6 \\
7 \\
8\end{array}$ & $\begin{array}{l}62 \\
78 \\
78 \\
69 \\
94 \\
82 \\
80 \\
95\end{array}$ & $\begin{array}{l}0.101 \\
0.101 \\
0.156 \\
0.080 \\
0.091 \\
0.131 \\
0.117 \\
0.088\end{array}$ & $\begin{array}{l}4.8 \\
5.0 \\
4.8 \\
5.3 \\
5.0 \\
4.5 \\
5.0 \\
5.3\end{array}$ & $\begin{array}{l}0.0108 \\
0.0100 \\
0.0071 \\
0.0112 \\
0.0111 \\
0.0095 \\
0.0086 \\
0.0103\end{array}$ \\
\hline $\begin{array}{l}\text { Mean } \\
\text { SE }\end{array}$ & 79 & $\begin{array}{l}0.108 \\
0.010\end{array}$ & $\begin{array}{l}\mathbf{5 . 0} \\
\mathbf{0 . 1}\end{array}$ & $\begin{array}{l}0.0098 \\
0.0005\end{array}$ \\
\hline \multicolumn{5}{|c|}{ Obese subjects } \\
\hline $\begin{array}{r}1 \\
2 \\
3 \\
4 \\
5 \\
6 \\
7 \\
8 \\
9 \\
10 \\
11 \\
12 \\
13 \\
14\end{array}$ & $\begin{array}{l}167 \\
185 \\
146 \\
138 \\
149 \\
150 \\
134 \\
118 \\
128 \\
118 \\
148 \\
114 \\
146 \\
132\end{array}$ & $\begin{array}{l}0.038 \\
0.050 \\
0.091 \\
0.095 \\
0.033 \\
0.050 \\
0.080 \\
0.086 \\
0.063 \\
0.116 \\
0.056 \\
0.052 \\
0.051 \\
0.031\end{array}$ & $\begin{array}{l}4.1 \\
4.0 \\
3.5 \\
4.0 \\
5.0 \\
4.4 \\
4.3 \\
4.0 \\
4.6 \\
4.2 \\
4.2 \\
4.5 \\
4.5 \\
5.0\end{array}$ & $\begin{array}{l}0.0398 \\
0.0316 \\
0.0267 \\
0.0166 \\
0.0306 \\
0.0264 \\
0.0171 \\
0.0185 \\
0.0189 \\
0.0124 \\
0.0256 \\
0.0239 \\
0.0246 \\
0.0328\end{array}$ \\
\hline $\begin{array}{l}\text { Mean } \\
\text { SE }\end{array}$ & 141 & $\begin{array}{l}0.064 \\
0.007\end{array}$ & $\begin{array}{l}4.3 \\
0.1\end{array}$ & $\begin{array}{l}0.0253 \\
0.0022\end{array}$ \\
\hline
\end{tabular}


TOTAL RESPIRATORY INERTANCE VS. BOOY WEIGHT

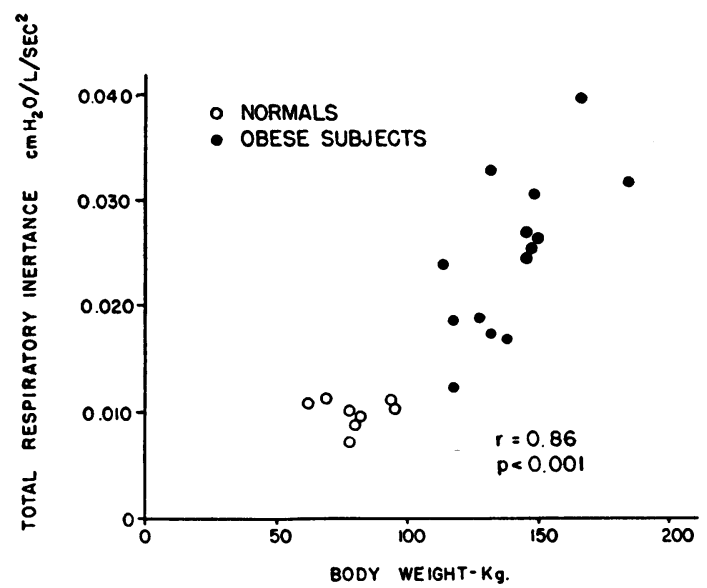

Fig. 3. The total Respiratory inertance plotted AGAINST BODY WEIGHT. The correlation is highly significant.

from a representative experiment in a single normal subject. The rather different values for gas and tissue inertances obtained from solution of the three sets of equations are probably due to the difficulty in determining precisely the natural frequency. In this subject the tissue inertance appears to constitute between $2 \%$ and $23 \%$ of the total respiratory inertance.

The first two columns of Table III give for the three normal and three obese subjects the effects of a unit change in gas density upon the natural frequency and upon the total inertance. The values were calculated from helium and $\mathrm{SF}_{6}$ data
TABLE II

Gas and tissue inertance data on normal subject $3^{*}$

\begin{tabular}{|c|c|c|c|}
\hline Gas breathed & $\begin{array}{c}\text { Mean gas } \\
\text { density } \\
\text { relative } \\
\text { to air as } 1.0\end{array}$ & 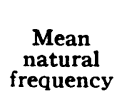 & $\begin{array}{c}\text { Total } \\
\text { inertance }\end{array}$ \\
\hline & & $c p s$ & $\underset{L / \text { second }^{2}}{\mathrm{H}_{2} \mathrm{O} /}$ \\
\hline $\begin{array}{l}\text { Air } \\
80 \% \mathrm{He} \\
80 \% \mathrm{SF}_{6}\end{array}$ & $\begin{array}{l}1.0 \\
0.43 \\
3.70\end{array}$ & $\begin{array}{l}4.4 \\
6.6 \\
2.5\end{array}$ & $\begin{array}{l}0.0084 \\
0.0037 \\
0.0260\end{array}$ \\
\hline \multirow[t]{2}{*}{$\begin{array}{l}\text { Paired } \\
\text { equations } \\
\text { solved }\end{array}$} & $\begin{array}{l}\text { Gas in- } \\
\text { ertance } \\
\text { (referred to } \\
\text { density of } \\
\text { air as 1.0) }\end{array}$ & $\begin{array}{c}\text { Tissue } \\
\text { inertance }\end{array}$ & $\begin{array}{c}\text { Tissue } \\
\text { inertance }\end{array}$ \\
\hline & \multicolumn{2}{|c|}{$\mathrm{cm}_{2} \mathrm{O} / \mathrm{L} /$ second $^{2}$} & $\%$ of total \\
\hline $\begin{array}{l}\mathrm{Air}-\mathrm{SF}_{6} \\
\mathrm{Air}-\mathrm{He} \\
\mathrm{SF}_{6}-\mathrm{He}\end{array}$ & $\begin{array}{l}0.0065 \\
0.0082 \\
0.0068\end{array}$ & $\begin{array}{l}0.0019 \\
0.0002 \\
0.0016\end{array}$ & $\begin{array}{r}23 \\
2 \\
19\end{array}$ \\
\hline Means & 0.0072 & 0.0012 & 15 \\
\hline
\end{tabular}

* Total compliance, $0.156 \mathrm{~L}$ per $\mathrm{cm} \mathrm{H}_{2} \mathrm{O}$.

by dividing the differences in natural frequency and in calculated total inertance encountered in each subject by the difference in mean gas density between the helium and $\mathrm{SF}_{\boldsymbol{B}}$ experiments. For example, utilizing data from Table II (normal subject 3 ), between helium and $\mathrm{SF}_{6}$ experiments, the difference in natural frequency was 6.6 to 2.5 or $4.1 \mathrm{cps}$, and the difference in inertance, 0.0260 to 0.0037 or $0.0223 \mathrm{~cm} \mathrm{H}_{2} \mathrm{O}$ per $\mathrm{L}$ per second ${ }^{2}$. Dividing these values by the difference in gas density, 3.70 to 0.43 or 3.27 yields the values $1.3 \mathrm{cps}$ and 0.0068 , the latter value being $81 \%$ of the total inertance breathing air. A unit

TABLE III

Total respiratory inertance and its components in 3 normal and 3 obese subjects

\begin{tabular}{|c|c|c|c|c|c|c|c|}
\hline Subject & $\begin{array}{c}\text { Change in } \\
\text { natural } \\
\text { frequency } \\
\text { per U } \\
\text { change in } \\
\text { gas } \\
\text { density }\end{array}$ & $\begin{array}{l}\text { Change in } \\
\text { total in- } \\
\text { ertance per } U \\
\text { change in } \\
\text { gas density ex- } \\
\text { pressed as \% of } \\
\text { total inertance } \\
\text { (breathing air) }\end{array}$ & $\begin{array}{c}\text { Total } \\
\text { respiratory } \\
\text { inertance }\end{array}$ & $\begin{array}{c}\text { Gas (air) } \\
\text { inertance }\end{array}$ & $\underset{\text { inertance }}{\text { Lung }}$ & Tissue & inertance \\
\hline & $c p s$ & & & $\mathrm{~cm} \mathrm{H}_{2} \mathrm{O} / L /$ second $^{2}$ & & & $\begin{array}{l}\% \text { of } \\
\text { total }\end{array}$ \\
\hline \multicolumn{8}{|l|}{ Normal } \\
\hline $\begin{array}{l}1 \\
2 \\
3\end{array}$ & $\begin{array}{l}1.3 \\
1.3 \\
1.2\end{array}$ & $\begin{array}{l}71 \% \\
85 \% \\
81 \%\end{array}$ & $\begin{array}{l}0.0092 \\
0.0105 \\
0.0084\end{array}$ & $\begin{array}{l}0.0085 \\
0.0079 \\
0.0072\end{array}$ & $\begin{array}{l}0.0055 \\
0.0070 \\
0.0094\end{array}$ & $\begin{array}{l}0.0007 \\
0.0026 \\
0.0012\end{array}$ & $\begin{array}{r}8 \\
25 \\
14\end{array}$ \\
\hline \multicolumn{8}{|l|}{ Obese } \\
\hline $\begin{array}{l}1(167) \\
2(185) \\
3(146)\end{array}$ & $\begin{array}{l}0.3 \\
0.5 \\
0.3\end{array}$ & $\begin{array}{r}9 \% \\
21 \% \\
19 \%\end{array}$ & $\begin{array}{l}0.0396 \\
0.0316 \\
0.0267\end{array}$ & $\begin{array}{l}0.0082 \\
0.0117 \\
0.0091\end{array}$ & $\begin{array}{l}0.0057 \\
0.0099 \\
0.0074\end{array}$ & $\begin{array}{l}0.0314 \\
0.0199 \\
0.0176\end{array}$ & $\begin{array}{l}79 \\
59 \\
66\end{array}$ \\
\hline
\end{tabular}


change in gas density produced a much smaller change in natural frequency and in inertance in the obese subjects than in the normals. These data imply that the major component in the excessively obese subject is tissue inertance.

The remainder of Table III summarizes the data on the gas and tissue components of the total inertance and also includes the lung inertances measured separately by the esophageal pressure method of Mead (4). The different values for total inertances given in Tables $I$ and III in normal subjects 1,2, and 3 are explained by the fact that data given in Table I were obtained in a separate determination a few days before the data in Table III were obtained. To this extent they represent the reproducibility of the total inertance measurement on separate days. Mead's data indicating that lung tissue inertance is virtually zero imply that lung and gas inertances should be very similar. Considering the many possibilities for inaccuracy of measurement in both lung and total inertance methods, the correspondence between lung and gas inertance in both obese and normal subjects may be considered reasonably good. The lung and gas inertance values in the obese subjects are in the same range as the normals, and their increased total inertance results solely from an increase in tissue inertance.

\section{Discussion}

Validity of the method. The meaning of the inertance measurements presented herein rests upon the validity of three assumptions that require examination. The first is that the respiratory system behaves essentially as a simple physical system. The second is that change in the density of the gas breathed produces no change in the effective compliance. The third is that the effective total compliance at the natural frequency is the same as that during slow breathing.

The assumption that the respiratory system behaves as a simple or "lumped" physical system means that its many elastic, inertial, and resistive elements may be faithfully represented by an appropriate arrangement of a single elastic, a single inertial, and a single resistive element. DuBois and associates (1) and Brody, DuBois, Nisell, and Engelberg (5) found that the response of the abdomen and lower chest to forced sinusoidal pres- sure waves at the mouth lags somewhat behind that of the upper thorax particularly at higher frequencies. They also describe in man and the cat propagated surface waves over the abdomen, which in the cat are unaffected by evisceration. In addition, Coermann, Ziegenruecker, Wittwer, and von Gierke (6) have compared in whole body oscillation ("shake table") experiments data obtained on intact supine man with calculations based upon a hypothetical model in which the lungs, thorax, and abdomen are assumed to be a simple or "lumped" system. The close correspondence between predicted and experimental data led the authors to conclude that the thoracicoabdominal system is a simple one with lumped physical parameters. These data indicate then that the assumption of a lumped system is clearly a simplification, although close enough to the truth to be useful.

The question of whether a change in gas density produces a change in compliance is also one for which there is no satisfactory answer. Any change in total compliance produced by altering the properties of the gas breathed would have to be in the lung compliance component. In the course of the present experiments, lung compliance measurements at slow breathing rates were made in normal subjects 1,2 , and 3 breathing air and the helium and sulphur hexafluoride mixtures. Breathing the heavy and light mixtures produced no significant differences in compliance. There is no available datum, however, nor methods for obtaining it, on whether breathing heavy gas mixtures alters effective compliance at oscillation frequencies near the respiratory system's natural frequency. One would predict, however, that if there were some inequality of time constants of terminal lung units tending to diminish effective compliance at higher frequencies, the presence of a heavy or a viscous gas in the respiratory system might accentuate this tendency by disproportionately increasing the resistance of the narrower airways. The likelihood of the gases used in the study causing a major change in effective lung compliance is slight because gas flow in the lower airways is almost wholly laminar (7), implying that flow resistance ought to be little affected by differences in gas density. Nor would the viscous airway resistances of terminal lung units be much affected by either of the foreign gases used 
in this study because their viscosities are close to that of air.

The third assumption, that the effective compliance at the natural frequency is the same as that determined at slow breathing rates, also defies verification by present methods. Mead (4) has, however, cited indirect evidence suggesting that the effective compliance of the respiratory system diminishes at frequencies approaching its natural frequency. He called attention to the observations of Dubois and co-workers (1) that the lower chest and abdomen oscillate in phase with the upper chest at frequencies below 2 cps but increasingly lag behind the upper chest at higher frequencies. This implies slight differences in time constants between different areas of the chest wall or underlying lung that are too small to be detectable at frequencies below 2 cps. That such a condition may prevail in the normal human lung is not unreasonable from anatomical considerations. The lungs of excessively obese persons probably contain regions of compressed lung, as evidenced by the mild arterial hypoxemia rectified by a deep breath seen in many of them (8). Seven of the obese subjects in this study had evidence of this. In such subjects time constant inequality of terminal lung units is very likely, which would make the differences between the effective compliance at slow and rapid cycling greater than in normals. Mead (4) points out that assuming the effective total compliance to be greater than it actually is results in an underestimation of total respiratory inertance. Hence the total inertance values may represent an underestimation in normals and a somewhat greater underestimation of the true value in the obese subjects.

An empirical validification of the method suggesting that the values for gas and tissue inertance are approximately correct is the reasonably close correspondence between lung and gas inertances in both normal and obese subjects. If Mead's data indicating that lung tissue inertance is virtually zero are correct, lung and gas inertances should be practically identical.

Precision of the method. The accuracy of inertance values obviously depends upon the accuracy with which the total compliance and the natural frequency may be measured. The accuracy and validity of total compliance measurements have been dealt with elsewhere $(9,10)$. Inspection of the expression used to calculate inertance, $I=$ $.0253 /\left(f_{n}\right)^{2} \cdot C$, reveals that, inasmuch as the natural frequency is squared in the denominator, an error in its determination will produce a much greater error in inertance than an error in measuring the total compliance. Moreover, the percentage of error resulting from a given error in measuring natural frequency will vary with frequency. A reasonable estimate of the average error of the natural frequency measurement is $\pm 0.5 \mathrm{cps}$ based on the reproducibility of measurements in single individuals and a consideration of the gap of 0.7 to $1.8 \mathrm{cps}$, over which frequency range the flow-pressure loop is closed. At $3 \mathrm{cps}$ an underestimate of $0.5 \mathrm{cps}$ would give a $40 \%$ overestimation of inertance, and an overestimate of 0.5 cps would result in a $30 \%$ underestimation of inertance. At $5 \mathrm{cps}$, underestimating the natural frequency by $0.5 \mathrm{cps}$ would cause a $24 \%$ overestimate in inertance, and a 0.5 cps overestimation would give a $17 \%$ underestimate of inertance. Assuming the highly unlikely situation that inertances in all the normals have been underestimated by $20 \%$ and inertances in all the obese overestimated by $30 \%$, the differences remain significant $(p<0.05)$ between the two groups, and tissue inertances are still impressively increased.

Implications of the data. In normal subjects breathing quietly, accelerations of from 2 to $10 \mathrm{~L}$ per second ${ }^{2}$ are encountered. These accelerations would require pressures of 0.02 to $0.10 \mathrm{~cm} \mathrm{H}_{2} \mathrm{O}$ in the normal subject and 0.08 to $0.40 \mathrm{~cm} \mathrm{H}_{2} \mathrm{O}$ in our obese subject with the greatest total inertance. During maximal ventilation maneuvers, we have measured accelerations between 200 and $500 \mathrm{~L}$ per second ${ }^{2}$, which would require pressures of 2 to $5 \mathrm{~cm} \mathrm{H}_{2} \mathrm{O}$ in the normal and 8 to $20 \mathrm{~cm} \mathrm{H}_{2} \mathrm{O}$ in obese subjects with the highest total inertances. During cough, although reliable measurements are not available, accelerations as great as 1,000 $\mathrm{L}$ per second ${ }^{2}$ probably occur, requiring inertance pressures of $10 \mathrm{~cm} \mathrm{H}_{2} \mathrm{O}$ in the normal and up to $40 \mathrm{~cm} \mathrm{H}_{2} \mathrm{O}$ in the excessively obese. Thus, while increased inertance may possibly have a limiting influence upon cough velocities and maximal ventilatory velocities in the excessively obese, it is probably of little importance in limiting ventilatory performance under less extreme circumstances. 
Another situation in which increased respiratory inertance may be detrimental is during abnormal body acceleration such as in low altitude operations in high performance aircraft and in certain phases of escape and re-entry during space flight. Magid, Coermann, and Ziegenruecker (11) have investigated the effects of whole body vibration over a frequency range of 1 to 20 cps. Because acceleration was of primary interest to these investigators, their experiments were done at uniform accelerations, with the result that displacements were very much greater at lower than at higher frequencies. At frequencies below $3 \mathrm{cps}$, dyspnea and air hunger were experienced, and at frequencies between 4 and $8 \mathrm{cps}$, dyspnea was replaced by a sensation of difficulty in making and controlling respiratory movements. The dyspnea experienced below 3 cps was thought to be related to the effects of the large displacements upon the pulmonary circulation as well as the thorax, whereas the somewhat different sensations experienced between 4 and $8 \mathrm{cps}$ were thought to be due solely to direct mechanical interference with the motions of the lungs and thorax. Their values for the natural frequency of the thorax and abdomen, using a shake table on supine subjects, were between 3.0 and $3.5 \mathrm{cps}$, somewhat below our normal mean of 5 cps. Differences in the method of applying the forced vibration and in the subjects' body position probably account for their lower natural frequencies. With their method the thorax and abdomen appeared to be underdamped rather than critically damped as found by DuBois and colleagues $(1,5)$.

\section{Summary}

1. Total respiratory compliance, respiratory system natural frequency, and total respiratory inertance were measured in 8 normal and 14 excessively obese subjects. The mean total inertance in the normals was $0.0098 \mathrm{~cm} \mathrm{H}_{2} \mathrm{O}$ per $\mathrm{L}$ per second $^{2}$, and that in the obese subjects, $0.0253 \mathrm{~cm}$ $\mathrm{H}_{2} \mathrm{O}$ per $\mathrm{L}$ per second ${ }^{2}$. This difference was highly significant $(p<0.001)$.

2. There were significant inverse correlations between total respiratory compliance and body weight $(r=-0.74)$ and between natural frequency and body weight $(r=-0.64)$. There was a significant positive correlation between total respiratory inertance and body weight $(r=+$ 0.86).

3. A method for estimating separately the gas and tissue components of total respiratory inertance is described and applied to three normal and three obese subjects.

4. In three normal subjects, tissue inertance averaged $16 \%$ of the total inertance. In three excessively obese subjects, tissue inertance averaged $68 \%$ of the total inertance.

\section{Acknowledgments}

The authors are grateful to Dr. Jere Mead for his valuable advice and criticism during the progress of this work and for his review of the manuscript. The technical assistance of Mr. Frank King, Mr. Andrew Miskowsky, and Miss Karin Ekstrand is also gratefully acknowledged.

\section{References}

1. DuBois, A. B., A. W. Brody, D. H. Lewis, and B. F. Burgess, Jr. Oscillation mechanics of lungs and chest in man. J. appl. Physiol. 1955, 8, 587.

2. Heaf, P. J. D., and F. J. Prime. The compliance of the thorax in normal human subjects. Clin. Sci. 1956, 15, 319.

3. Mead, J. Control of respiratory frequency. J. appl. Physiol. 1960, 15, 325.

4. Mead, J. Measurement of inertia of the lungs at increased ambient pressure. J. appl. Physiol. 1956, 9, 208.

5. Brody, A. W., A. B. DuBois, O. I. Nisell, and J. Engelberg. Natural frequency, damping factor and inertance of the chest-lung system in cats. Amer. J. Physiol. 1956, 186, 142.

6. Coermann, R. R., G. H. Ziegenruecker, A. L. Wittwer, and $H$. E. von Gierke. The passive dynamic mechanical properties of the human thorax-abdomen system and of the whole body system. Aerospace Med. 1960, 31, 443.

7. Ferris, B. G., Jr., L. Opie, and J. Mead. Partitioning of respiratory resistance in man. Fed. Proc. 1960, 19, 377.

8. Said, S. I. Abnormalities of pulmonary gas exchange in obesity. Ann. intern. Med. 1960, 53, 1121.

9. Sharp, J. T., J. P. Henry, S. K. Sweany, W. R. Meadows, and R. J. Pietras. The effects of mass loading the respiratory system in man. Submitted for publication.

10. Sharp, J. T., J. P. Henry, S. K. Sweany, W. R. Meadows, and R. J. Pietras. The total work of breathing in normal and obese men. Submitted for publication.

11. Magid, E. B., R. R. Coermann, and G. H. Ziegenruecker. Human tolerance to whole body sinusoidal vibration. Aerospace Med. 1960, 31, 915. 